\title{
Para além dos estudos de uso da informação arquivística: a questão da acessibilidade
}

\author{
Luciana Ferreira da Costa \\ Mestre em ciência da informação pela Universidade Federal \\ da Paraíba (UFPb), Brasil. Professora do Departamento de \\ Ciência da Informação da Universidade Federal da Paraíba \\ (UFPb), PB, Brasil. \\ E-mail: lucianna.costa@yahoo.com.br
}

\begin{abstract}
Alan Curcino Pedreira da Silva
Doutorando pelo Programa Integrado de Doutorado em Filosofia das Universidades Federais da Paraíba, Pernambuco e Rio Grande do Norte (Pidfil-UFPB/UFPE/UFRN), Brasil. Mestre em ciência da informação pela Universidade Federal da Paraíba (UFPb), Brasil. Professor da Universidade Federal de Alagoas (Ufal), AL, Brasil.

E-mail: alancurcino@hotmail.com
\end{abstract}

\section{Francisca Arruda Ramalho}

Doutora em ciência da informação pela Universidad Complutense de Madrid (UCM), Espanha. Professora do Departamento de Ciência da Informação da Universidade Federal da Paraíba (UFPb), PB, Brasil.

E-mail: arfrancisca@hotmail.com

\section{Resumo}

Este artigo objetiva discutir a questão da acessibilidade no âmbito dos estudos de uso da informação arquivística. Apontando os arquivos como importantes unidades de informação e o papel da arquivologia na contemporaneidade, aborda a concepção dos estudos híbridos de uso da informação no contexto arquivístico a partir da definição dos estudos de usuários. Neste contexto, discute a acessibilidade quanto à informação em unidades de informação arquivística por meio do direito à informação; do acesso físico; do acesso às tecnologias da informação e comunicação; e do acesso intelectual. Destaca a iniciativa de arquivos acessíveis na internet. Conclui com a proposta de promoção dos estudos híbridos de uso da informação voltados à questão da inclusão e da acessibilidade, ampliando a abordagem "arquivos direcionados para os usuários", tratando o acesso à informação arquivística a partir do seu direito instituído.

\section{Palavras-chave}

Arquivologia. Informação arquivística. Arquivo. Estudos de usuários. Usabilidade. Acessibilidade.

\section{Further studies of archival information use: the issue of accessibility}

\begin{abstract}
The objective of this article is to present arguments about the issue of accessibility in the context of the studies of how archival information is used. The archives are pointed out as important units of information as well as the role of archival science at the present times. The concept of hybrid studies of information use is approached in the archival context according to the users' studies. In this context, accessibility is discussed in regard to the information in archival information units in accordance with the right to information; physical access; access to information and communication technologies; and intellectual access. The initiative of accessible archives is underlined. The conclusion is a proposal for promoting the hybrid studies of information use concerning the issue of inclusion and accessibility with a broad approach to the "archives aimed at the users", treating the access to archival information based on institutional right.
\end{abstract}

\section{Keywords}

Archival science. Archival information. Archive. User studies. Usability. Accessibility.

\section{MAPOTECAS SOCIAIS: A ARQUIVÍSTICA EM CENA!}

... Naquele Império, a Arte da Cartografia chegou a tal Perfeição que o Mapa de uma Província ocupava toda uma Cidade, e o Mapa do Império, toda uma Província. Com o tempo, esses Mapas desmesurados já não bastavam mais. Os Colégios de Cartógrafos elaboraram um Mapa do Império que tinha a imensidão do próprio Império e coincidia perfeitamente com ele. Mas as Gerações Seguintes, menos afeitas ao Estudo da Cartografia, pensaram que este Mapa enorme era inútil e, não sem Impiedade, abandonaram-no as Inclemências do Sol e dos Invernos. Nos Desertos do Ocidente ainda sobrevivem Ruínas dilaceradas do Mapa, habitadas por Animais e mendigos; em todo o País, 
não existe nenhuma outra Relíquia das Disciplinas Geográficas. ${ }^{1}$

A atual era da informação, assim denominada por Castells $(1999,2000,2001)$, tem sido marcada por grandes e significativas mudanças na sociedade, na economia e na cultura, no modo de ser, agir e pensar das pessoas, em consequência da (r)evolução das tecnologias da informação e comunicação (TIC) cada vez mais presentes no cotidiano humano. Isto, da cultura do virtual e instauração de novas redes de comunicação e de conhecimento (LÉVY, 1999; JOHNSON, 2001; LEMOS, 2002), à globalização e sua mais emergente face, a economia da informação, quando a própria informação se torna insumo econômico, valor agregado a produtos ou novo capital (LASTRES; ALBAGLI, 1999).

Como refere Barreto (2002, p. 1), neste momento histórico "a informação é qualificada como um instrumento modificador da consciência e da sociedade como um todo". Vivemos o império da informação!

É importante salientar que, entretanto, num país repleto de desajustes sociais, econômicos e políticos como o Brasil, por exemplo, ainda sobrevivem, parafraseando Borges, ruínas dilaceradas no seu mapa, habitadas por animais e mendigos. A disponibilidade ou a possibilidade de acesso à informação não quer dizer que ela esteja sendo usada de modo eficaz, que pode gerar conhecimento na sociedade.

Milton Santos (1994) advertiu-nos acerca da existência de pontos fixos sociais de concentração de informações e produção de conhecimento, comunicados por fluxos de produtos, pessoas e informação, beneficiando/desenvolvendo seus territórios, em detrimento de outros territórios marginalizados. De outro ângulo, corroborando seu pensamento a Santos, Martin (1995) denomina

\footnotetext{
${ }^{1}$ Jorge Francisco Isidoro Luis Borges encontrada n'O rigor da Ciência, que está em sua obra de contos intitulada Historia Universal de La Infâmia. Aqui utilizamos uma tradução contida em Silva Filho (1997, p. 125).
}

a sociedade atual como sociedade global da informação, disposta no território mundial por lugares onde aparecem comunidades informadas e outras não informadas, existindo níveis diversos intermediários de informação entre esses locais.

Nessa perspectiva, a democratização da informação deve, como um processo de inclusão social, auxiliar o indivíduo a ter condições de elaborar o insumo recebido, transformando-o em conhecimento que lhe traga benefícios (BAGGIO, 2000; BARRETO, 2002). Ressalta-se o papel das unidades de informação como instituições sociais responsáveis pela realização e promoção de práticas informacionais, de exigência políticosocial e epistemológica de que estas sejam cada vez mais justas, democráticas e acessíveis compreendendo-se práticas informacionais como práticas sociais, culturais e educativas de tratamento, organização e comunicação da informação, como geração, transferência, difusão/disseminação, armazenamento, recuperação e uso da informação (ARAÚJO, 1998; MARTELETO, 1992).

São consideradas unidades de informação, portanto, organizações ou setores que têm por objetivo atender às necessidades de utilização, geração e transferência de informação de determinada área, oferecendo informações que possam agregar valor às atividades desenvolvidas no contexto em que se inserem. A principal finalidade de uma unidade informacional é articular a relação entre as diversas fontes de informação e as pessoas, considerando seus perfis e necessidades sob a influência de certos ambientes. (BARRETO; IBICT, 1997)

Não só as bibliotecas, museus, arquivos e centros de informação e documentação são considerados unidades de informação; diante das características e exigências da era da informação, também outras organizações e os diversos setores intraorganizacionais responsáveis pelo gerenciamento da informação documental e arquivística e das próprias TICs utilizadas institucionalmente, sejam elas organizações públicas, privadas ou do $3^{\circ}$ setor (organizações não governamentais).

Ci. Inf., Brasília, DF, v. 39 n. 2, p.129-143, maio/ago., 2010 
Temos, então, associações, órgãos públicos e empresas de informação, setores organizacionais como núcleos de tecnologia da informação, setores de processamento de dados, telemarketing etc. Diante da profusão das unidades de informação surge uma leva de trabalhadores dedicados à organização e tratamento da informação nessas instituições, embora muitas vezes não sendo especializados ou devidamente capacitados, como no caso daqueles que lidam com os arquivos. Lopez (2008, p. 1) observa: "Ser arquivista no Brasil de hoje não é o mesmo que exercer a profissão de arquivista".

Extrapolando a dimensão de habeas data do acesso à informação como instituição do Direito Público, mais do que nunca fica evidente a necessidade da organização e do tratamento da informação para subsidiar processos decisórios organizacionais (de gestores e colaboradores), para prover informações aos usuários externos das organizações (financiadores, investidores, avaliadores, auditores, clientes, consulentes ou público-alvo, parceiros etc). As práticas de organização e tratamento devem promover e subsidiar pesquisas e a produção de novos conhecimentos ou solução de problemas, bem como promover o exercício da cidadania e o empoderamento social contra formas de intolerância e preconceito, conforme indicam autores como Davenport (2000), Tarapanoff (2001), Cruz (2002), Choo (2003) e Aquino (2008).

Diante desse quadro, evolui a arquivologia (ou arquivística) como campo científico preocupado com um dos produtos mais naturais do homem, os documentos (nos mais diversos suportes ou mídias, do tradicional papel ao meio eletrônico: recortes, folhetos, catálogos, documentos oficiais, correspondências, mapas, áudios, imagens, etc), tendo como objeto de estudo a informação aí inscrita, denominada documental ou arquivística e implicada no próprio desenvolvimento humano.

Para Paes (2004), a arquivologia é o estudo, a ciência ou a arte dos arquivos. E os arquivos, segundo conceituação geral adotada pela comunidade arquivística brasileira, refere-se a:
Designação genérica de um conjunto de documentos produzidos e recebidos por uma pessoa física ou jurídica, pública ou privada, caracterizado pela sua natureza orgânica de sua acumulação e conservado por essas pessoas ou por seus sucessores, para fins de prova ou informação (PAES, 2004, p. 24).

Não podemos negligenciar, conforme enfatiza Lopez (2008, p. 5), que os arquivos estão presentes em todas as esferas sociais, por tratarem dos documentos como produtos das múltiplas atividades da organização e gestão humana. Se pela fábula de Borges, mapas de províncias ocupam muitas cidades, e os mapas dos impérios, diversas províncias, então percebemos que a voz do imperador Justiniano ainda ecoa em todo o mundo:

Que sua eminência ordene em todas e em cada uma das províncias que se reserve um prédio público no qual o magistrado (defensor) guarde os documentos, escolhendo alguém que os mantenha sob custódia, de forma que não sejam adulterados e possam ser encontrados rapidamente por quem os solicite; que entre eles haja arquivos e seja corrigido tudo que foi negligenciado nas cidades. (JUSTINIANO apud SCHELLENBERG, 2006, p. 23).

Replicando-se exponencialmente na atualidade a voz de Justiniano, nove problemáticas vivenciadas pelo campo arquivístico são levantadas por Jardim (2009, p. 1-2):

$1^{a}$ problemática - emersão de novas práticas informacionais arquivísticas diante das TICs: "As atuais tecnologias da informação fomentam um 'espaço virtual' com funcionamento e características próprias que produzem novas configurações de produção, fluxo e acesso à informação";

$2^{a}$ problemática - a internet como locus múltiplo e em constante transformação da prática informacional arquivística;

$3^{\text {a }}$ problemática - o acesso à informação como nova palavra de ordem: "O conceito de "lugar" torna-se secundário para o profissional da informação e para os usuários. Onde a informação se encontra não é o mais importante e sim o acesso à informação"; 
$4^{a}$ problemática - foco no acesso, fluxo e redes de informação: "A ênfase na gestão da informação desloca-se do acervo para o acesso, do estoque para o fluxo da informação, dos sistemas para as redes";

$5^{a}$ problemática - a relativização do tempo, cada vez mais secundário, para a exigência do conceito de instantaneidade das práticas informacionais arquivísticas;

$6^{a}$ problemática - reconfiguração (modernização) das unidades de informação arquivística, renovando e superando suas funções históricas;

$7^{\mathrm{a}}$ problemática - reconhecimento de pessoas excluídas dos serviços de unidades de informação arquivística (principalmente pelo não acesso às TIC) ao mesmo tempo da solicitação de novas demandas dos seus usuários inferindo na $6^{\mathrm{a}}$ problemática;

$8^{a}$ problemática - a dificuldade enfrentada em face das exigidas mudanças na gestão da informação arquivística por parte de suas organizações (a questão da cultura organizacional): "A tendência às alterações nas formas de gerenciar, disseminar a informação e administrar os recursos a ela relacionados (humanos, tecnológicos etc.) é um processo lento, complexo e contraditório, em especial no caso dos países dependentes"; e

$9^{a}$ problemática - emersão de novas práticas de gestão da informação arquivística diante dos espaços informacionais virtuais (bibliotecas digitais, arquivos eletrônicos etc).

De forma complementar, Lopes (2009, p. 3) aponta para a necessidade de uma nova configuração da arquivologia, o que ele denominou "arquivística que precisamos":

A arquivística que precisamos deverá dar conta no plano prático e teórico dos problemas de nosso tempo. Ela não pode continuar a ter um perfil de subordinação que a anula no plano teórico e a limita no plano da prática. Precisa ser interdisciplinar não no discurso, mas sim na prática e na teoria. Necessita ser internacional para atender os ditames da globalização, da consequente troca de informações entre governos e sociedades em escala planetária. Não pode ser burocrática e formalista, sem resolver problemas concretos, fazendo de conta que tudo está pronto, que nada há a pesquisar e a resolver. Não pode ser espontaneísta, resolvendo caso a caso, sem qualquer metodologia de suporte. Não deve ignorar a pesquisa e ser fechada a qualquer contribuição das demais disciplinas do conhecimento humano. Deve ser mais do que a expressão de um país ou região determinada, sendo algo que tenha universalidade.

Atentando às problemáticas levantadas por Jardim e à "arquivística que precisamos" aconselhada por Lopes, em face da importância das unidades de informação arquivística na conceituada era da informação, é demandada à arquivologia a promoção de uma formação e de uma prática cada vez mais atualizada tecnologicamente e mais aproximada ao usuário de sua informação, de modo ético e democrático. Pelo acesso à informação, como palavra de ordem, a questão da acessibilidade se evidencia nesse contexto.

A acessibilidade se refere à qualidade do acesso, de ser acessível. Refere-se à condição do acesso aos serviços de informação, comunicação e documentação (FERREIRA, 2004). A própria Associação dos Arquivistas Brasileiros ressalta o dever da facilitação do acesso à informação arquivística de maneira imparcial ao maior número de pessoas, conforme discriminado nos Princípios Éticos do Arquivista (AAB, 2009).

Por essa compreensão, apresentamos o cerne deste trabalho, o de proposição da promoção de estudos mais inclusivos por parte da arquivologia, do uso da informação a partir do seu acesso, entendendo a arquivologia como formação superior, campo científico e campo de atuação profissional, contribuindo para tornar os diversos arquivos mais acessíveis na efetividade da promoção do uso de suas informações. 


\section{PELOS ESTUDOS DE USO DA INFORMAÇÃO ARQUIVÍSTICA}

Os primeiros estudos orientados aos usuários de informação, mais minuciosamente enfocando a maneira como os cientistas e técnicos procediam para obter informação (comportamento na busca da informação), ou como usavam a literatura de suas áreas (uso da biblioteca do Museu de Ciência de Londres), surgiram a partir dos trabalhos de Bernal e Urquhart, apresentados em 1948 na Conferência de Informação Científica da Royal Society of London (BERNAL, 1948; URQUHART, 1948). A partir daí, os estudos de usuários passaram por diferentes fases durante a segunda metade do século XX, sendo evolutivamente incorporados às práticas de pesquisa da ciência da informação (FERREIRA, 2002; CHOO, 2003).

Em uma definição clássica de estudos de usuários, Figueiredo (1979, p. 79) os trata como:

[...] investigações que se fazem para se saber o que os indivíduos precisam, em matéria de informação, ou então, para saber se as necessidades de informação, por parte dos usuários de um centro de informação, estão sendo satisfeitas de maneira adequada.

Esses estudos, para a referida autora, são canais de comunicação que se abrem entre os sistemas de informação e a comunidade à qual eles servem.

Sanz Casado (1994), inspirado na metodologia científica, definiu estudos de usuários como "o conjunto de estudos que trata de analisar, qualitativa e quantitativamente, os hábitos de informação dos usuários".

Por essas definições clássicas, percebemos porque Guinchat e Menou (1994) consideram o usuário como o elemento fundamental de todo e qualquer sistema de informação e justificam a necessidade de estudos de usuários.

A temática "necessidades e usos de informação" englobando os estudos de usuários se manteve no ranking de frequência das temáticas mais publicadas no Annual Review of Information Science and Tecnology (Arist) nas penúltimas três décadas, ocupando o terceiro lugar de publicações sob o enfoque social da ciência da informação (PINHEIRO, 1997).

$\mathrm{Na}$ última década, entretanto, os estudos de usuários se voltaram para o comportamento informacional e para a avaliação de satisfação e desempenho do usuário em seu processo de busca e uso de informação, com ênfase na relação entre usuários e sistemas de informação interativos no contexto social das TICs (COSTA, 2008). Esta tendência vem promovendo um diálogo profícuo entre a ciência da informação principalmente com as ciências sociais, a educação, as ciências cognitivas, a ciência da computação, a engenharia de software e a engenharia da produção, utilizadas como lastro para atuais estudos de usuários no contexto social das TICs (KIT'TUR; CHI; SUH, 2008; BAPTISTA; CUNHA, 2007; BOHMERWALD, 2005; COSTA, 2008; COSTA; SILVA; RAMALHO, 2009; COSTA; RAMALHO, 2010).

No início desse período, Wilson (1999; 2000) propôs novo modelo de compreensão dos estudos de usos e usuários da informação, chamado comportamento informacional, referindo-se a esse tipo de comportamento como todas as ações executadas pelo indivíduo em direção às fontes e aos canais informacionais, concretizando o uso da informação. Daí a sua proposição não se referir tão somente ao novo modelo, mas também à adoção do termo comportamento informacional em detrimento do termo estudo de usuários, por considerar o primeiro de âmbito mais abrangente (WILSON, 2000), ideia que vem influenciando diversos pesquisadores.

O tema 'comportamento informacional' tem sido bastante explorado no Arist. Substitui a nomenclatura utilizada nos trabalhos anteriormente denominados 'necessidades e uso de informação'. Em termos quantitativos, foram 15 revisões até o momento, sendo que a década de 1970 mostra-se a mais profícua (cinco revisões) apesar de a década de 2000, ainda não completada, mostrar-se com boa produtividade 
(quatro). Considerando-se a evolução dos estudos de comportamento informacional desde a primeira revisão do Arist (1966), até a última, em 2009, percebem-se mudanças significativas no foco dos trabalhos [...] (GASQUE; COSTA, 2010, p. 31).

Apesar de a proposta de Wilson ser adotada na última década por parte de pesquisadores da área, argumentos contrários foram levantados, sustentados “na ideia de que o termo 'comportamento' poderia ser associado inapropriadamente ao paradigma behaviorista da psicologia", além de que, "da ótica semântica, o termo seria inadequado pelo fato de que informação não possui comportamento" (GASQUE; COSTA, 2010, p. 29). Somando-se a tais argumentos, não se pode negar a tradição do termo estudos de usuários, herdada da biblioteconomia e documentação, presente até os dias atuais no discurso e na prática da ciência da informação (DIAS; PIRES, 2004; BAWDEN, 2006; DERVIN; REINHARD, 2006; SOUTO; DERVIN; SAVOLAINEN, 2008; COSTA; SILVA; RAMALHO, 2009; KUO; PERRIG; WALKER, 2009).

Gasque e Costa (2010, p. 21) a esse respeito asseveram sobre o cenário brasileiro:

Embora se observe no Brasil, nos últimos anos, a emergência de pesquisas intituladas Comportamento Informacional de Usuários, em geral tais investigações ainda são conhecidas como "estudos de necessidades", contidos no tópico "estudos de usuários".

Sobre o cenário brasileiro, em pesquisa recente, Araújo identificou 190 artigos sobre estudos de usuários publicados em sete dos principais periódicos da área da ciência da informação do país, entre os anos de 1998 e 2007. Para Araújo, na validação da importância dos estudos de usuários, sua pesquisa possibilitou a visualização de:

[...] um perfil do que se tem feito no campo de estudos de usuários no Brasil, e acredita-se que principalmente a prática de pesquisa e a prática de ensino nas disciplinas de usuários da informação, nas várias instâncias em que ocorrem (cursos de graduação em Biblioteconomia, Arquivologia, Museologia, Sistemas de Informação; cursos de pós-graduação em Ciência da Informação, entre outras) possam ser enriquecidas com os resultados aqui encontrados (ARAÚJO, 2009, p. 25).

No cenário mundial, duas abordagens teóricometodológicas têm sido promovidas quando da realização dos estudos de usuários: a primeira, mais antiga, intitulada abordagem tradicional (FERREIRA, 2002) ou paradigma clássico (FIGUEIREDO, 1999); e a mais recente intitulada abordagem alternativa (FERREIRA, 2002) ou paradigma moderno (FIGUEIREDO, 1999). A primeira abordagem tem como foco o sistema, as unidades de informação e seus produtos. Diferentemente, a segunda abordagem vem focando o usuário, sendo atualmente mais privilegiada por perspectivas cognitivas, psicossociais e holísticas.

Seguindo a tradição científica, tanto a nomenclatura quanto a prática formativo-profissional dos estudos de usuários foram absorvidas pelo universo arquivístico (KURTZ, 1990; VALDEHITA MAYORAL, 2007; AGUILAR, 2008; BARROS, 2008; GARCÍA GÓMEZ, 2008; LUCAS, 2008; RUBIO HERNÁNDEZ, 2008; SANTAELLA RUIZ, 2001; 2009).

$\mathrm{Na}$ arquivologia, os estudos de usuários, segundo Jardim e Fonseca (2004, p. 1), partiram do modelo arquivos direcionados para os arquivistas, como abordagem tradicional, para o modelo arquivos direcionados para os usuários, como abordagem alternativa. Os autores sublinham que "é cada vez mais ressaltado que arquivistas não servem aos arquivos, mas à sociedade e seus diversos agentes". Podemos afirmar, portanto, que os arquivos (considerados como organização e sistema) devem servir aos usuários, ou, como é mais usual na literatura arquivística, devem servir à comunidade ou público-alvo.

No modelo de arquivos direcionados para os usuários, urge, portanto, perguntar para que se destina a informação e não para quem se destina a informação, considerando que um usuário pode se incluir em várias categorias. Tais categorias se referem à compreensão do usuário como um ator 
social, apresentando diferentes papéis na sociedade: estudante, docente, pesquisador, administrador, cidadão-comum, entre outros (GUINCHAT; MENOU, 1994; SANZ CASADO, 1994; COSTA, 2008). Assim, as necessidades de informação dos usuários dependem de suas atividades profissionais, área de interesse etc., enfim, variam de acordo com suas funções desempenhadas no cotidiano.

Jardim e Fonseca (2004) realizaram uma revisão de literatura com o intuito de aprofundar o debate sobre os estudos de usuários no contexto arquivístico, destacando o conhecimento publicado nas últimas três décadas. Sua pesquisa revelou diversas constatações, entre as quais destacamos:

- a literatura arquivística sobre estudos de usuários é incipiente, ou seja, pouco expressiva;

- no que tange aos estudos de usos e usuários de arquivos, não se contempla uma literatura que investigue este tema do ponto de vista prático e teórico; e

- a preocupação com o acesso aos arquivos não parece estar plasmada numa perspectiva de relação/ diálogo envolvendo arquivista, arquivos e usuários.

Faz-se, dessa forma, cada vez mais necessário que a literatura aborde o tema da interação entre usuário, arquivo e arquivistas. Deve-se atentar para a importância de reconhecer não só as necessidades informacionais do primeiro, a partir das necessidades de seu acesso ao próprio arquivo e seus sistemas de informação, bem como observar a qualidade dessa interação principalmente no contexto atual de uso das TICs e seus sistemas baseados em computador, na assunção do papel de gestor da informação pelo arquivista.

Stair (1998, p. 13) expõe a composição dos sistemas de informação baseados em computador por seis elementos: hardware, software, banco de dados, telecomunicações (redes), pessoas (usuários) e procedimentos. Já para Pressman (1995, p. 179), os sistemas de informação baseados em computador combinam seus elementos de muitas maneiras com o objetivo final de transformar dados em informações, e em outra perspectiva convergente à de Stair, acrescenta a documentação como mais um elemento desses sistemas, referindo-se a "manuais, formulários e outras informações descritivas que retratam o uso e/ou operação do sistema". E sobre as pessoas, Pressman ainda as discriminam em usuários e operadores, as últimas tanto de hardware quanto de software.

Mas como verificar a qualidade da interação dos usuários de arquivos versus sistemas?

A qualidade de interação nesse contexto é uma questão de usabilidade.

Não foi à toa que, conforme Baptista e Cunha (2007), as últimas décadas ilustraram a fase qualitativa dos estudos de usuários, utilizando não só teorias de autores das áreas da ciência da informação e da comunicação social, bem como, recentemente, da usabilidade.

Para Dias (2003, p. 29), "usabilidade é uma qualidade de uso de um sistema, diretamente associada ao seu contexto operacional e aos diferentes tipos de usuários, tarefas, ambientes físicos e organizacionais". Nessa perspectiva, a usabilidade está ligada ao diálogo promovido pela interface com a máquina e à capacidade de alcance dos usuários acerca de seus objetivos de interação com o sistema.

Ao analisar a usabilidade, é correto afirmar que ao fazê-la pensamos no usuário, no início, no fim e sempre, desde a criação ao desenvolvimento de um sistema, pois a interface entre usuário-sistema implica a usabilidade. Nesse sentido, Nielsen (1993), precursor dos estudos de usabilidade, afirma que um bom sistema interativo deve proporcionar cinco vantagens aos seus usuários: facilidade de aprendizado, eficiência de uso, facilidade de memorização, baixa taxa de erros e satisfação subjetiva.

Para Pressman (1995), a usabilidade é uma tentativa de se avaliar a user friendliness como uma medida de qualidade, que, traduzida ao português, significa amigabilidade ao usuário, ou qualidade de um 
sistema baseado em computador ser amigável ao usuário. "Se um programa não for user friendly frequentemente estará destinado ao fracasso, mesmo que as funções que ele execute sejam valiosas" (PRESSMAN, 1995, p. 71).

O termo usabilidade começou a ser usado na década de 1980 como um substituto da expressão userfriendly, traduzida ao português como amigável, sobretudo para as áreas de psicologia e ergonomia, migrando para a ciência da computação e engenharia de software e de usabilidade, e apenas mais recentemente para o campo da ciência da informação (COSTA, 2008).

Deve-se, então, atentar ao fato de que os estudos de usabilidade não têm origens na ciência da informação. Até porque, nas suas origens tais estudos se voltaram à interação do homem com produtos tecnológicos, do homem com máquinas, não necessariamente interação entre pessoas através desses produtos ou interação com fins à comunicação e informação. Estes estudos se consolidaram na evolução do trabalho de quase duas décadas de pesquisadores da ciência da computação e engenharia de software e de usabilidade (QUEIROZ, 2001; NIELSEN; LORANGER, 2007; CYBIS, 2007).

Para Queiroz (2001), a engenharia de usabilidade surge como uma área de investigação resultante do amadurecimento e sistematização das suas pesquisas denominadas estudos de usabilidade, visando a direcionar o processo de desenvolvimento da usabilidade de produtos tecnológicos interativos, acompanhando a evolução das TICs. Por tal razão, com base em Cybis (2007), Costa e Ramalho (2010) citam como alvos principais dos estudos de usabilidade na atualidade: e-commerce/e-business, jogos de computador, software de gestão, TV digital, telefones celulares, pagers, palmtops, laptops, handhelds, wireless devices, até wearables.

Apesar da propensa apropriação dos estudos de usabilidade pelos estudos de usuários abrangendoos, seja para uma classificação temática das práticas de pesquisa ou reserva metadiscursiva, vários autores da ciência da informação vêm corroborando a perspectiva de diálogo e complementaridade entre tais estudos. Como exemplo, podemos citar Bohmerwald (2005), Paiva e Ramalho (2006), Ferreira e Pithan (2008), Araújo e Curty (2008), Costa (2008), Costa e Ramalho (2009; 2010), Costa, Silva e Ramalho (2009), Araújo (2010) e Chiu (2010).

Nesse contexto, Bohmerwald (2005, p. 95) considera que se a pesquisa acerca de um sistema específico de informação e seus usuários abordasse características tanto dos estudos de usuários quanto dos estudos de usabilidade, isto apontaria para a possibilidade de se conseguir uma análise mais completa.

No âmbito da ciência da informação, Costa e Ramalho (2010, p. 113) denominaram "esse fazer dialógico entre os estudos de usuários e os estudos de usabilidade como estudos híbridos de uso da informação". Araújo (2010, p. 18) ressalta a proposta de Costa e Ramalho como uma iniciativa que possibilita uma mescla entre contribuições teóricas sobre aspectos cognitivos do comportamento informacional com as potencialidades interativas dos sistemas digitais de informação, como os estudos de usabilidade, através, portanto, de modelos híbridos.

Adotando-se neste artigo a proposta dos estudos híbridos de uso da informação como profícua para o campo da arquivologia, seguem as indicações de Costa e Ramalho (2010, p. 113-114) quando se referem a especiais sistemas interativos de informação como campos de interseção de tais estudos:

Entram em cena os aplicativos/software de gerenciamento de recursos informacionais, as bibliotecas digitais, os repositórios digitais temáticos ou institucionais de documentos, os bancos de teses e dissertações, as enciclopédias virtuais, os periódicos eletrônicos, as bases de dados eletrônicas, os portais de informação, etc., vinculando-se a temáticas como arquitetura de informação, ergonomia, design centrado no usuário, acessibilidade, portabilidade, funcionalidade, ontologias, web semântica, folksonomia, e isto diante do possível conhecimento e intervenção sobre o desempenho e a satisfação dos usuários quando do uso desses sistemas e seus recursos. 
Na paráfrase de Costa e Ramalho (2010), dedicandose a compreender o comportamento humano quando da busca e uso de informações documentais ou arquivísticas, os estudos híbridos de uso da informação podem incorrer/contribuir para a própria promoção do desenvolvimento das pessoas e de seus contextos sociais. Dessa forma, estudos híbridos de uso da informação arquivística devem ser realizados pelas diversas unidades de informação arquivística para avaliação, otimização e ampliação de seus serviços, promovendo cada vez mais a recuperação, o acesso e o uso de suas informações por parte de seus usuários.

\section{PELA ACESSIBILIDADE DOS ARQUIVOS: INICIATIVAS INCLUSIVAS}

Para promover arquivos mais acessíveis, propomos que estudos híbridos de uso da informação arquivística devam se voltar à questão da inclusão, da acessibilidade, ampliando o modelo arquivos direcionados para os usuários, associando, para tanto, as questões para quem se destina a informação à para que se destina a informação. Pois o para quem, aqui, referir-se-á não só aos diversos papéis desempenhados pelos usuários, mas também aos seus diversos contextos e necessidades, por vezes "especiais" (de aprendizagem, de mobilidade, de comunicação, etc.), intervenientes no acesso à informação. Conforme o inciso I do Art. $2^{\circ}$ da Lei $n^{\circ} 10.098$ de 2000, a definição de acessibilidade se refere à:

[...] possibilidade e condição de alcance para utilização, com segurança e autonomia, dos espaços, mobiliários e equipamentos urbanos, das edificações, dos transportes e dos sistemas e meios de comunicação, por pessoa portadora de deficiência ou com mobilidade reduzida.

Dessa forma, tais estudos devem atentar ao acesso à informação arquivística a partir do seu direito instituído, como direito à informação, o qual, para Jardim (2009 p. 2), é considerado:

[...] expressão de uma terceira geração de direitos dos cidadãos - carrega em si uma flexibilidade que o situa não apenas como um direito civil, mas também como um direito político e um direito social, compondo uma dimensão historicamente nova da cidadania.

Jardim (2009 p. 2-3) observa que "o direito à informação transforma, ao menos teoricamente, o território administrativo em território partilhado, em espaço de comunicação".

Quando nos deparamos, contudo, com a estimativa da Organização Mundial de Saúde (OMS) (SCHWARZ; HABER, 2001), de que $10 \%$ da população mundial têm algum tipo de deficiência ou incapacidade, a questão do direito de acesso à informação arquivística se amplia do espaço de comunicação ao acesso propriamente dito em sua dimensão física e em sua relação às TICs utilizadas pelas unidades de informações arquivísticas através de seus sistemas.

Correia, Correia e Frassinetti (2009, p. 1), ainda sobre a questão do direito à acessibilidade, fazem uma advertência a que devemos atentar: "TODOS apresentamos algum tipo de desajustamento em relação à norma, em termos sociais motores, do tipo de inteligência predominante, dos estilos de aprendizagem preferenciais, das capacidades preponderantes".

A segunda perspectiva de acesso à informação arquivística se refere ao acesso físico, já que no Brasil a exigência legal é restrita apenas aos espaços públicos ou privados de promoção a serviços públicos ou a grande coletividade. Dessa maneira, esse tipo de acesso vem sendo comumente promovido apenas por arquivos públicos e similares, referindo-nos ao âmbito arquivístico.

A legislação em referência se trata do Decreto $n^{\circ}$ 3.298 de 1999, que dispõe sobre a Política Nacional para a Integração da Pessoa Portadora de Deficiência e consolida as normas de sua proteção; da Lei n ${ }^{\circ}$ 10.098 de 2000, que estabelece normas gerais e critérios básicos para a promoção da acessibilidade das pessoas portadoras de deficiência ou com mobilidade reduzida; e da Lei $\mathrm{n}^{\circ} 7.853$ de 1989, que dispõe sobre o apoio às pessoas portadoras de 
deficiência, sua integração social, sobre a criação da Coordenadoria Nacional para Integração da Pessoa Portadora de Deficiência (Corde), sobre a tutela jurídica jurisdicional de interesses coletivos ou difusos dessas pessoas, sobre a disciplina da atuação do Ministério Público, e a definição de crimes nesse contexto.

Como terceira perspectiva de acesso à informação arquivística, surge o acesso às TICs. Segundo Correia, Correia e Frassinetti (2009), o acesso às TICs se refere a uma série de possibilidades alternativas de acesso inclusivo à informação mediante tipos de hardware e software desenhados em sintonia com o conceito de desenho universal e ergonomia. Ao favorecer a biodiversidade humana natural, o desenho universal - como conjunto de conhecimentos que visam à concepção de produtos utilizáveis com eficácia, segurança e conforto contribui para a melhoria da qualidade de uso de sistemas e da qualidade de vida como um todo. Ajustando-se o desenho universal à ergonomia, a última vem a ultrapassar o conceito de maior adaptabilidade à anatomia do ser humano.

Correia, Correia e Frassinetti (2009) classificam o acesso às TICs atentando aos quatro tipos de acessibilidade descritas em sequência:

a) acessibilidade motora - sempre que as formas de acesso tradicional ao computador através do teclado e do mouse não são as mais adequadas, é possível utilizar periféricos alternativos muito diversificados. Exemplos: teclados de conceitos; teclados virtuais; emuladores de mouse; mouses adaptados; comutadores ou switches; comando através da voz; ativação dos elementos da página através do teclado etc.

b) acessibilidade auditiva - no que tange a essa categoria, ainda há caminho longo a trilhar, e as tecnologias emergentes precisam se estabilizar e democratizar. Campo promissor é a conversão automática de texto em língua gestual. Exemplos: softwares de tradução automática; leitor de página Web com sintetização de fala; legendagem de documentos etc; c) acessibilidade visual - existência de normas de acessibilidade que visam a atender à forma particular como as pessoas com baixa visão ou deficiência visual acedem à informação digital (encontrada na internet ou em $c d$-rom). Exemplos: sistemas que convertem texto escrito em texto Braille; função de aumento do texto com as opções do navegador de sites etc;

d) acessibilidade cognitiva - por vezes, as barreiras que impedem o acesso à informação e dificultam a comunicação são de natureza cognitiva. Ao falarmos ou escrevermos, nossas palavras atuam como símbolos do que queremos dizer, mas as pessoas impossibilitadas de utilizar palavras de forma tradicional necessitam utilizar outros sistemas de símbolos que lhes sejam acessíveis, para que possam transmitir suas mensagens aos demais. Exemplos: os diversos programas de símbolos inteligentes disponíveis para computador.

Diante dessa tipologia de acessibilidade, que ora relacionamos à informação arquivística, Correia, Correia e Frassinetti (2009, p. 3) chamam atenção ao conceito convergente de software inclusivo, como sendo "todo aquele que é concebido, desenvolvido e comercializado de modo a ser acessível ao maior número possível de utilizadores, incluindo pessoas com deficiência". Para nós, software inclusivo pode ser utilizado como um suporte estratégico de gestão das unidades de informação arquivística em prol da respeitabilidade às necessidades especiais dos seus usuários internos e externos quanto às suas práticas de armazenamento, recuperação, gerenciamento e preservação de documentos, desde a sua criação e uso até o expurgo e destruição final, conforme determinações legais e especificações institucionais.

No contexto da internet, a flexibilidade da informação e a interface entre o usuário e o respectivo suporte de apresentação caracterizam a acessibilidade. A flexibilidade da informação, nesse contexto, refere-se ao uso da informação por pessoas com necessidades especiais através de vários equipamentos ou navegadores em diferentes ambientes e situações (CERTIC, 2009).

Ci. Inf., Brasília, DF, v. 39 n. 2, p.129-143, maio/ago., 2010 
Sobre as interfaces entre usuários-sistemas, Pressman (1995, p. 608) explica que, desde a década de 1970, estas foram definidas pela comunicação e interação entre ambos através dos seguintes atributos: janelas, ícones, menus e dispositivos de indicação, associados, desde o limiar do século, ao hipertexto e a multitarefa. Hipertexto como o conjunto de textos organizados por relações remissivas em meio eletrônico, no qual suas remissões correspondem a comandos que permitem ao usuário acessar os elementos associados (FERREIRA, 2004), e multitarefa como "a capacidade de executar uma série de diferentes tarefas simultaneamente (a partir do ponto de vista do usuário)" (PRESSMAN, 1995, p. 608).

Atentando à flexibilidade da informação e à interface entre usuário-sistema, o Centro de Engenharia de Reabilitação e Acessibilidade (2009) considera que a acessibilidade na internet deve envolver os conceitos de utilizadores, situação e ambiente, descritos como segue:]

- O termo "utilizadores" significa que nenhum obstáculo é imposto ao indivíduo face às suas capacidades sensoriais e funcionais;

- O termo "situação" significa que o sistema é acessível e utilizável em diversas situações, independentemente do software, comunicações ou equipamentos;

- O termo "ambiente" significa que o acesso não é condicionado pelo ambiente físico envolvente, exterior ou interior.

Como iniciativas acessíveis, é certo que alguns arquivos vêm promovendo sua acessibilidade mesmo através da internet. Podemos citar, por exemplo, os casos de um arquivo digital e outro de um arquivo tradicional com disponibilização de acesso através desse canal virtual de comunicação e informação.

O primeiro caso se refere ao Arquivo da Web Portuguesa (2009), que, conforme seu site oficial, foi projetado "para ser completamente acessível e utilizável, funcionando em conformidade com as Directivas para a Acessibilidade do Conteúdo da Web (WCAG v1.0) e em conformidade com as especificações da W3C".

O Consórcio World Wide Web (W3C) engloba centenas de empresas, órgãos governamentais e organizações independentes, além de uma equipe em tempo integral trabalhando para desenvolver estratégias, guias e recursos para acessibilidade à Web, visando ao crescimento democrático do seu acesso e uso. Por sua vez, os documentos das WCAG visam explicar como produzir conteúdos web (textos, imagens, formulários, sons e correlatos) acessíveis às pessoas portadoras de necessidades especiais (W3C, 2010). Nesse sentido, o Arquivo da Web Portuguesa compreende a acessibilidade na prática desde tamanho dos textos até mesmo às teclas de acesso.

O outro exemplo se refere ao Arquivo Distrital de Bragança, que em todo seu site oficial apresenta na barra inferior o símbolo internacional de acessibilidade na internet, a fechadura no globo com meridianos. Todavia, apesar da apresentação do símbolo, o arquivo adverte a não garantia total da promoção da acessibilidade:

A afixação do símbolo de acessibilidade não garante que este sítio seja 100\% acessível. A utilização deste símbolo demonstra, unicamente, um esforço em aumentar a acessibilidade deste sítio em conformidade com a Resolução do Conselho de Ministros 97/99 [Portugal] sobre a acessibilidade dos sítios da Administração Pública na Internet pelos cidadãos com necessidades especiais (ADB, 2009).

Mesmo que os diversos arquivos promovam a acessibilidade como indicada neste trabalho, a efetividade do processo de uso da informação só estará garantida se acrescentarmos aí a questão do dispositivo intelectual. Jardim aponta para o último, quiçá o mais importante tipo de acessibilidade a se investigar, promover e exigir, referindo-se ao acesso intelectual:

A noção de acesso à informação relaciona-se, portanto, a um direito, mas também a dispositivos políticos, culturais, materiais e intelectuais que garantam o exercício efetivo desse direito. $\mathrm{O}$ acesso 
jurídico à informação não se consolida sem o acesso intelectual à informação. $\mathrm{O}$ acesso jurídico à informação pode garantir ao usuário o acesso físico a um estoque informacional materialmente acessível (um "arquivo" no subsolo de um organismo governamental, por exemplo) sem que seja possível o acesso intelectual dada a ausência de mecanismos de recuperação da informação. As experiências internacionais e, em especial o caso brasileiro, deixam claro que não se viabiliza o direito à informação governamental sem políticas públicas de informação. (JARDIM, 2009, p. 3)

\section{CONSIDERAÇÕES FINAIS}

Considerando o insigne papel social dos arquivos como unidades de informação, evidenciado na promoção de práticas informacionais democráticas e acessíveis, visando a entender como interferem nas necessidades e usos de informação por parte dos usuários, urge que ainda percorramos um caminho que otimize a relação arquivista, arquivo e usuário, atentando que o último é o elemento essencial neste relacionamento.

Assim, no universo arquivístico, tal relacionamento deve ser abordado pelos estudos híbridos de uso da informação sob um modelo de arquivos direcionados para os usuários, englobando suas demandas informacionais e necessidades, incluindo as consideradas especiais, atentando para a qualidade da interação do usuário com a unidade de informação arquivística.

Os estudos híbridos de uso da informação arquivística podem revelar as possíveis barreiras de informação e comunicação das organizações arquivísticas e seus sistemas, desde as barreiras sociais, o que possibilita a criação de alternativas/ estratégias de enfrentamento e modificações/ajustes do modus operandi do sistema ou da organização em parte ou como um todo. Promover-se-ia, portanto, a acessibilidade, e daí a integração social das pessoas com necessidades especiais.

Propomos, dessa forma, que os estudos híbridos de uso da informação arquivística devam se voltar à questão da inclusão e da acessibilidade, avaliando- as e promovendo-as, ampliando o modelo arquivos direcionados para os usuários, tratando o acesso à informação arquivística a partir do seu direito instituído.

Nesse sentido, este trabalho ressalta os estudos híbridos de uso da informação para o campo arquivístico, desde o ponto de vista teórico ao prático, na preocupação do uso da informação segundo a qualidade do seu acesso.

Não há dúvida de que os estudos de uso da informação têm muito a contribuir para os campos da arquivologia e da ciência da informação em diálogo, tanto no âmbito teórico quanto prático, sublinhando questões que envolvam o usuário. Este trabalho se apresenta, também, como reflexão para o campo científico-profissional da arquivologia, na tentativa de contribuir para uma prática inclusiva realizada por seus profissionais em seus diversos campos de atuação, numa perspectiva humanista, destacando justamente o ser humano, aquele que usa a informação. De outra forma, arquivistas com necessidades especiais seriam integrados nesse contexto de promoção de inclusão pelo seu trabalho.

Logo, a questão da acessibilidade é relacionada a três fatores: o primeiro social (referindo-se ao combate ao preconceito e à promoção da integração das pessoas com necessidades especiais); o segundo institucional (de promoção da acessibilidade pelas diversas unidades de informação arquivística na sociedade); e o terceiro formativo-profissional (referente à implicação na tríade arquivista-arquivosusuários). Exige-se, portanto, uma tomada de consciência global.

Somente atentando a esses fatores - pedindo licença para última paráfrase realizada a Borges - sem impiedade serão encontradas relíquias documentárias da nossa disciplina arquivística, permitindo a construção de outras mais relíquias, ultrapassando resilientemente o passado, quando tantas pessoas e documentos foram abandonados às inclemências do sol e dos invernos.

Artigo submetido em 02/05/2009 e aceito em 10/02/2011.

Ci. Inf., Brasília, DF, v. 39 n. 2, p.129-143, maio/ago., 2010 
Para além dos estudos de uso da informação arquivística: a questão da acessibilidade

\section{REFERÊNCIAS}

AQUINO, Mirian de Albuquerque. A informação nas estratégias educativas de recusa à intolerância em contextos reais/virtuais. Disponível em: < http:/ / www.bocc.ubi.pt/pag/aquino-mirian-informacao-intolerancia.pdf $>$. Acesso em: 20 set. 2008.

ARAÚJO, Carlos Alberto Ávila. Abordagem interacionista de estudos de usuários da informação. Ponto de Acesso, Salvador, v.4, n.2, p. 2-32, set. 2010 .

Um mapa dos estudos de usuários da informação no Brasil. Em Questão, Porto Alegre, v. 15, n. 1, p. 11-26, jan./jun. 2009.

ARAÚJO, Eliany Alvarenga de. A construção social da informação: práticas informacionais no contexto de Organizações Não-Governamentais/ ONGs brasileiras. 1998. 221 f. Tese (Doutorado em Ciência da Informação)-Universidade de Brasília, Brasília, 1998.

ARAUJO, Nelma Camelo de; CURTY, Renata Gonçalves. Análise da usabilidade de interfaces de repositório institucional: enfoque em uma ferramenta baseada em princípios ergonômicos. In: ENCONTRO NACIONAL DE PESQUISA E PÓS-GRADUAÇÃO EM CIÊNCIA DA INFORMAÇÃO, 9., 2008, São Paulo. Anais... São Paulo: ENANCIB, 2008.

ARQUIVO DA WEB PORTUGUESA (AWP). Acessibilidade. Disponível em: <http://arquivo-web.fccn.pt/accessibility-info $>$. Acesso em: 15 abr. 2009.

ARQUIVO DISTRITAL DE BRAGANCA (Portugal). Acessibilidade e Disposições Legais. Disponível em: < http://adbraganca.iantt.pt/acess. php>. Acesso em: 15 abr. 2009.

ASSOCIAÇÃO DOS ARQUIVISTAS BRASILEIROS (AAB). Princípios Éticos do Arquivista. Disponível em: <http://www.aab.org. $\mathrm{br} /$ index.php?option $=$ com_content\&view $=$ article\&id $=69 \&$ Itemid $=65 \&$ lang $=\mathrm{pt}>$. Acesso em: 21 mar. 2009.

BAGGIO, Rodrigo. A sociedade da informação e a infoexclusão. Ciência da Informação, Brasília, v. 29, n. 2, p. 16-21, maio/ago. 2000.

BAPTISTA, Sofia Galvão; CUNHA, Murilo Bastos da Cunha. Estudo de usuários: visão global dos métodos de coleta de dados. Perspectiva em Ciência da Informação, Belo Horizonte, v. 12, n. 2, mai./ago. 2007.

BARRETO, Aldo de Albuquerque. A questão da informação. Disponível em: <http://aldoibct.bighost.com.br/quest/quest2.pdf >. Acesso em: 14 jan. 2002.

BARRETO, Auta Rojas; Instituto Brasileiro de Informação Científica e Tecnológica (IBICT). Gestão de unidades de informação: manual. Curitiba: TECPAR; Brasilia: IBICT, 1997.

BARROS, Dirlene Santos. Dimensões metacognitivas no comportamento de busca da informação: estudo de usuário no Arquivo Público do Estado do Maranhão (APEM). 2008. 158f. Dissertação (Mestrado em Ciência da Informação)-Universidade Federal da Paraíba, João Pessoa, 2008.

BAWDEN, David. Users, user studies and human information behaviour: a three-decade perspective on Tom Wilson's "On user studies and information needs". Journal of Documentation, v. 62, n. 6, p.671-679, 2006.
BERNAL, John Desmond. Preliminary analysis of pilot questionnaire on the use of scientific literature. In: THE ROYAL SOCIETY SCIENTIFIC INFORMATION CONFERENCE, 21 jun.-2 jul. 1948, London, Proceedings: reports and papers submitted. London: The Royal Society, 1948.

BOHMERWALD, Paula. Uma proposta metodológica para avaliação de bibliotecas digitais: usabilidade e comportamento de busca por informação na Biblioteca Digital da PUC - Minas. Ciência da Informação, Brasília, DF, v. 34, n.1, p.95-103, jan./abr. 2005.

CASTELLS, Manuel. A era da informação: economia, sociedade e cultura. São Paulo: Paz e Terra, 1999. (A sociedade em rede, v.1).

A era da informação: economia, sociedade e cultura. 3.ed. São Paulo: Paz e Terra, 2001. (O poder da identidade, v.2).

A era da informação: economia, sociedade e cultura. 2.ed. São Paulo: Paz e Terra, 2000. (Fim de milênio, v.3).

CENTRO DE ENGENHARIA DE REABILITAÇÃO E ACESSIBILIDADE (CERTIC). Acessibilidade.net. Disponível em: <http://www.acessibilidade.net/web/>. Acesso em: 12 abr. 2009.

CHIU, Ming-Hsin. Making Sense of Library 2.0 through Technological Frames. The American Society for Information Science and Technology, Proceedings... Pittsburgh, PA, USA, october 22-27, 2010.

CHOO, Chun Wei. A organização do conhecimento: como as organizações usam a informação para criar significado, construir conhecimento e tomar decisões. São Paulo: Editora Senac, 2003, cap. 2, p. 63-126.

CORREIA, Secundino; CORREIA, Patrícia; FRASSINETTI, Ese de Paula. Acessibilidade e Desenho Universal. Disponível em: < http:// actividades.imagina.pt/uploads/cnoti/PDF/desenho_universal. pdf>. Acesso em: 15 fev. 2009.

COSTA, Luciana Ferreira da. Usabilidade do Portal de Periódicos da CAPES. 2008. 236 f. Dissertação (Mestrado em Ciência da Informação)-Centro de Ciências Sociais Aplicadas, Universidade Federal da Paraíba, 2008. Disponível em: <http://dci2.ccsa.ufpb. br: $8080 /$ jspui/bitstream/123456789/99/3/Dissertação\%20 Luciana\%20Costa.pdf>. Acesso em: 30 dez. 2008.

COSTA, Luciana Ferreira da; RAMALHO, Francisca Arruda. Para onde vai a tecnologia? Ensaio social sobre tecnologia, informação e conhecimento. Biblioteca On-line de Ciências da Comunicação, BOCC, Universidade Beira-Interior, Covilhã, Portugal, abr., p. 1-13, 2008.

A usabilidade nos estudos de uso da informação: em cena, usuários e sistemas interativos de informação. Perspectivas em Ciência da Informação, v. 15, n. 1, p. 92-117, jan./abr. 2010.

COSTA, Luciana Ferreira da; SILVA, Alan Curcino Pedreira da; RAMALHO, Francisca Arruda. (Re)visitando os Estudos de Usuário: entre a "tradição" e o "alternativo". DataGramaZero, Rio de Janeiro, v.10, n. 4, p. 1-12, ago. 2009. Disponível em: <http://www. datagramazero.org.br/ago09/Art_03.htm>.

CRUZ, Tadeu. Gerência do conhecimento: enterprise content management. São Paulo: Cobra Editora e Marketing, 2002. 
CYBIS, Walter. Ergonomia e Usabilidade: conhecimentos, métodos e aplicações. São Paulo: Novatec Editora, 2007.

DAVENPORT, Thomas H. Ecologia da Informação: porque só a tecnologia não basta para o sucesso na era da informação. Tradução de Bernadette Siqueira Abrão. São Paulo: Futura, 2000.

DERVIN, Brenda; REINHARD Carrie Lynn D. Researchers and practitioners talk about users and each other. Making user and audience studies matter. Information Research, v. 12, n.1, oct. 2006.

DIAS, Cláudia. Usabilidade na web: criando portais mais acessíveis. Rio de Janeiro: Alta Books, 2003.

DIAS, Maria Matilde Kronka; PIRES, Daniela. Usos e usuários da informação. São Carlos: EdUFSCar, 2004.

FERREIRA, Aurélio Buarque de Holanda. Novo Dicionário Aurélio Eletrônico da Lingua Portuguesa versão 5.0. 3.ed. São Paulo: Editora Positivo, 2004.

FERREIRA, Sueli Mara Pinto. Estudo de necessidades de informação: dos paradigmas tradicionais à abordagem Sense-Making. Disponível em $<$ http://www.eca.usp.br/nucleos/sense/index.htm>. Acesso em: 14 jan. 2002.

FERREIRA, Sueli Mara Pinto; PITHAN, Denise Nunes. Estudos de usuários e de usabilidade na Biblioteca INFOHAB: relato de uma experiência. Disponível em: <http://bibliotecas-cruesp.usp. br/3sibd/docs/ferreira662.pdf >. Acesso em: 20. jan. 2008.

FIGUEIREDO, Nice Menezes de. Paradigmas modernos da Ciência da Informação. São Paulo: Polis, 1999.

GARCÍA GÓMEZ, Juan Carlos. Usabilidad de las páginas de inicio de los diarios digitales españoles. Disponível em: <http://www.um.es/ gtiweb/juancar/curri/scire_garciagomez_2004.pdf>. Acesso em:16 dez. 2008.

GASQUE, Kelley Cristine Gonçalves Dias; COSTA, Sely Maria de Souza. Evolução teórico-metodológica dos estudos de comportamento informacional de usuários. Ciência da Informação, Brasília, v. 39, n. 1, p. 21-32, jan./abr. 2010.

GUINCHAT, Claire; MENOU, Michel. Usuários. In: Introdução geral às técnicas da informação e da documentação. Brasília: IBICT, 1994. p. 481-491.

JARDIM, José Maria. O acesso à informação arquivística no Brasil: problemas de acessibilidade e disseminação. Disponível em: $<$ http://www.conarq.arquivonacional.gov.br/Media/publicacoes/ mesa/o_acesso_informao_arquivstica_no_brasil.pdf > . Acesso em 12 jan. 2009.

JARDIM, José Maria.; FONSECA, Maria Odila. Estudos de usuários em arquivos: em busca de um estado da arte. DataGramaZero - Revista de Ciência da Informação, v. 5, n. 5, out. 2004. Disponível em: < http:// www.datagramazero.org.br/out04/Art_04.htm>.

JOHNSON, Steven. Cultura da interface: como o computador transforma nossa maneira de criar e comunicar. Trad. Maria Luisa Borges. Rio de Janeiro: Jorge Zahar, 2001.
KITTUR, Aniket; CHI, Ed H.; SUH, Bongwon. Crowdsourcing user studies with Mechanical Turk. In: ANNUAL SIGCHI CONFERENCE ON HUMAN - CHI'08, 26., 2008. Proceedings... New York, NY, USA, 2008.

KUO, Cynthia; PERRIG, Adrian; WALKER, Jesse. Designing user studies for security applications: a case study with wireless network configuration. International Journal of Security and Networks, v. 4, n. 1-2, p. 101-109, 2009.

KURTZ, Clara Marli Scherer. O usuário do Arquivo Nacional e o sen relacionamento com os serviços oferecidos para a satisfação de suas necessidades de informação. 1990. Dissertação (Mestrado em Ciência da Informação)Instituto Brasileiro de Informação em Ciência e Tecnologia, Universidade Federal do Rio de Janeiro, Rio de Janeiro, 1990.

LASTRES, Helena M. M.; ALBAGLI, Sarita (Orgs.). Informação e Globalização na Era do Conhecimento. Rio de Janeiro: Campus, 1999.

LE COADIC, Yves. A Ciência da Informação. Brasília: Briquet de Lemos, 1994.

LEMOS, André. Cibercultura. Tecnologia e vida social na cultura. Porto Alegre: Sulina, 2002.

LÉVY, Pierre. Cibercultura. São Paulo: Ed. 34, 1999.

LOPES, Luís Carlos. Os arquivos, a gestão da informação e a reforma do Estado. Disponível em: <http://www.camara.gov.br/internet/ infdoc/novoconteudo/acervo/temas/luiscarlos.pdf $>$. Acesso em: 15 jan. 2009.

LOPEZ, André Porto Ancona. O "ser" e o "estar" arquivista no Brasil de hoje. In: CONGRESSO BRASILEIRO DE ARQUIVOLOGIA, 15., 2008, Goiânia. Anais... Goiânia: AAB/AAG, 2008. Disponível em: <http://www.aag.org.br/anaisxvcba/conteudo/resumos/ mesa_redonda2/andreporto.pdf $>$. Acesso em: 30 nov. 2008.

LUCAS, André et al. Estudo de usuário como estratégia para Gestão da Informação e do Conhecimento: um estudo de caso. Revista $A B C$. Florianópolis, v. 13, n. 1, p. 59-79, jan./jun. 2008.

MARTELETO, Regina Maria. Cultura, Educação e Campo Social: discursos e práticas de informação. 1990. Tese (Doutorado em Comunicação)-Escola de Comunicação. Universidade Federal do Rio de Janeiro, Rio de Janeiro, 1992.

MARTIN, W. J. The global information society. London: ASLIB Gower, 1995.

MENA AGUILAR, Adriana. Los estudios de usuarios en archivos: importancia y metodologia para su realización. Disponível em: $<$ http://www.archivonacional.go.cr/V\%20Seminario/Adriana $\% 20$ Mena.ppt>. Acesso em: 16 dez. 2008.

NIELSEN, Jakob. Usability Engineering. San Diego: Academic Press, 1993.

NIELSEN, Jakob; LORANGER, Hoa. Usabilidade na web: projetando websites com qualidade. Rio de Janeiro: Editora Campus, 2007.

PAES, Marilena Leite. Arquivo: teoria e prática. 3.ed. Rio de Janeiro: Editora FGV, 2004.

Ci. Inf., Brasília, DF, v. 39 n. 2, p.129-143, maio/ago., 2010 
Para além dos estudos de uso da informação arquivística: a questão da acessibilidade

PAIVA, Eliane; RAMALHO, Francisca Arruda. Usabilidade de softwares: um estudo com bibliotecas universitárias do nordeste brasileiro. In: SEMINÁRIO NACIONAL DE BIBLIOTECAS UNIVERSITÁRIAS, 14., 2006, Salvador. Anais... Salvador: UFBA, 2006.

PINHEIRO, Lena Vânia Ribeiro. A ciência da informacão: entre sombra e luz: domínio epistemológico e campo interdisciplinar. 1997. 278f. Tese (Doutorado em Comunicação)-Universidade Federal do Rio de Janeiro, Rio de Janeiro, UFRJ, 1997.

PRESSMAN, Roger S. Engenharia de software. São Paulo: Markron Books, 1995.

QUEIROZ, José Eustáquio Rangel de. Abordagem hibrida para a avaliação da usabilidade de interfaces com o usuário. 2001. 410f. Tese (Doutorado em Engenharia Elétrica)-Universidade Federal da Paraíba, Campina Grande, 2001.

RUBIO HERNÁNDEZ, Alfonso. Estudios de usuarios en archivos municipales: una aproximación teórico-práctica. Disponível em: <http://wotan.openlib.org/dois/data/Articles/juliccrgy:2004:v:10 :i:1:p:217-236.htm>. Acesso em: 16 dez. 2008.

SANTAELLA RUIZ, Rita Dolores. Estudios de usuarios de arcbivos de la ciudad de Jaén. 2001. Tese (Doctorado en Ciencias de la Información)Universidade de Granada, Granada, 2001.

Metodologia de estudios de usuarios de información: estúdio de casos en la Administración Pública. Revista Textos de la CiberSociedad. n. 5. Disponível em: <http://www.cibersociedad.net/textos/articulo. php?art=61>. Acesso em: 10 jan. 2009.

SANTOS, Milton. Técnica espaço tempo: globalização e meio técnicocientífico-informacional. São Paulo: Hucitec, 1994.

SANZ CASADO, Elias. Manual de estudios de usuarios. Madrid: Pirâmide, 1994.

SCHELLENBERG, Theodore R. Arquivos modernos: princípios e técnicas. 6.ed. Rio de Janeiro: Editora FVG, 2006.
SCHWARZ, A., HABER, J. (Orgs.). Guia São Paulo adaptada 2001. São Paulo: O Nome da Rosa, 2001.

SILVA FILHO, Waldomiro. Razões do Pragmatismo: significação e verdade no ambiente do ceticismo. In: DIAS, Andre Luis Mattedi; et al. (Orgs.). Perspectivas em epistemologia e história das ciências. Feira de Santana: UFFS, 1997. p. 123-133.

SOUTO, Patrícia; DERVIN, Brenda; SAVOLAINEN, Reijo. Designing for knowledge worker informings: an exemplar application of sense-making methodology. The American Society for Information Science and Technology, USA, v. 45, n. 1., 2008.

STAIR, Ralph M. Princípios de sistemas de informação: uma abordagem gerencial. 2.ed. Rio de Janeiro: LTC Editora, 1998.

TARAPANOFF, Kira (Org.). Inteligência organizacional e competitiva. Brasília: UnB, 2001.

URQUHART, Donald J. The organization of the distribution of scientific and technical information. In: THE ROYAL SOCIETY SCIENTIFIC INFORMATION CONFERENCE, 21 jun./2 jul. 1948, London. Proceedings: reports and papers submitted. London: The Royal Society, 1948.

VALDEHITA MAYORAL, Maria Teresa. Los usuarios en el archive general de la Universidad Nacional de Educación a Distancia (UNED) . Revista General de Información y Documentación, Madrid, v. 17, n. 2, 2007. Disponível em: <http://revistas.ucm.es/portal/modulos. php?name $=$ Revistas2_Historico\&id=RGID\&num + RGID070722 $>$. Acesso em: 28 nov. 2007.

WILSON, T. D. Exploring models of information behavior: the 'uncertainty' project. Information Processing and Management, Elmsford, NY, v.35, n.6, p. 839-849, nov. 1999.

Human information behavior. Informing Science Research, v.3, n. 2 , p. 49-55, 2000.

WORLD WIDE WEB CONSORTIUM (W3C). Escritório Brasil. Sobre o Consórcio W3C. Disponível em: <http://www.w3c.br/>. Acesso em: 01 fev. 2010. 